\title{
Epidermolysis Bullosa Acquisita
}

National Cancer Institute

\section{Source}

National Cancer Institute. Epidermolysis Bullosa Acquisita. NCI Thesaurus. Code C84690.

A chronic autoimmune inflammatory disorder characterized by the formation of subepidermal blisters in the skin and the mucous membranes. 